\title{
Fabrication of a Textured Non-Magnetic Ni-12at.\%V Alloy Substrate for Coated Conductors
}

Gao, M. M.; Grivel, Jean-Claude; Suo, H. L.; Yue, Zhao; He, Dong; Andersen, Niels Hessel

Published in:

I E E E Transactions on Applied Superconductivity

Link to article, DOI:

10.1109/TASC.2010.2090631

Publication date:

2011

Document Version

Publisher's PDF, also known as Version of record

Link back to DTU Orbit

Citation (APA):

Gao, M. M., Grivel, J-C., Suo, H. L., Yue, Z., He, D., \& Andersen, N. H. (2011). Fabrication of a Textured NonMagnetic Ni-12at.\%V Alloy Substrate for Coated Conductors. I E E E Transactions on Applied Superconductivity, 21(3), 2973-2976. https://doi.org/10.1109/TASC.2010.2090631

\section{General rights}

Copyright and moral rights for the publications made accessible in the public portal are retained by the authors and/or other copyright owners and it is a condition of accessing publications that users recognise and abide by the legal requirements associated with these rights.

- Users may download and print one copy of any publication from the public portal for the purpose of private study or research.

- You may not further distribute the material or use it for any profit-making activity or commercial gain

- You may freely distribute the URL identifying the publication in the public portal 


\title{
Fabrication of a Textured Non-Magnetic Ni-12at.\%V Alloy Substrate for Coated Conductors
}

\author{
M. M. Gao, J.-C. Grivel, H. L. Suo, Y. Zhao, D. He, and N. H. Andersen
}

\begin{abstract}
Ni-12at.\% V alloy is a promising candidate for non-magnetic cube textured metallic substrates used for high temperature coated conductors. In this work, a textured Ni-12at.\%V substrate has been fabricated by powder metallurgy route. After cold rolling and recrystallization annealing, a cube texture content as high as $99 \%\left(<10^{\circ}\right)$ was obtained, and the low angle grain boundary fraction is $89 \%$. In addition, the FWHM values of phi-scan and rocking curve are $7.77^{\circ}$ and $7.37^{\circ}$, respectively. According to micro-hardness measurement, the $\mathrm{HV}$ value of $\mathrm{Ni}-12 \mathrm{at} . \% \mathrm{~V}$ tape is three times higher than that of pure $\mathrm{Ni}$ and to a certain extent higher than that of Ni-5at.\%W. Furthermore, the Curie temperature of the Ni-12at.\% V substrate is decreased to less than $77 \mathrm{~K}$ due to the addition of vanadium element in $\mathrm{Ni}$.
\end{abstract}

Index Terms-Coated conductor, cube texture, magnetization loss, Ni alloy.

\section{INTRODUCTION}

I N RECENT years the Ni-W alloy substrates have been investigated extensively worldwide due to their suitability for coated conductor applications. The substrate must provide a sharp cube texture, high yield strength and oxidation resistance to satisfy the practical requirements during epitaxial growth of buffer layers and superconducting layers [1], [2]. In particular, the Ni-5at.\%W(Ni5W) alloy substrate is a attractive candidate alloy and could be produced in hundred-meter scale long tapes by several companies or institutes [3]-[5]. However, the Curie temperature of the Ni5W alloy is $335 \mathrm{~K}$, which means that the ferromagnetism might be a problem and limit the practical applications of the coated conductor even at $77 \mathrm{~K}$ (viewed to be the highest working temperature of the coated conductors).

Within the development of non-magnetic textured substrates, several Ni based binary alloys [6]-[8] and ternary alloys [9], [10] have been prepared and characterized on the basis of their mechanical strength, magnetic property and cube texture. Due

Manuscript received August 01, 2010; accepted October 27, 2010. Date of publication December 10, 2010; date of current version May 27, 2011. This work was supported by the Danish Agency for Science Technology and Innovation under Project 09-065234, and by the Danish-Chinese Center for Nanometals under Grant 50911130230.

M. M. Gao is with the College of Materials Science and Engineering, Beijing University of Technology, Beijing 100124, People's Republic of China. He is also with the Materials Research Division, Ris $\emptyset$ National Laboratory for Sustainable Energy, Technical University of Denmark, 399 Frederiksborgvej, 4000 Roskilde, Denmark.

J.-C. Grivel, Y. Zhao, D. He, and N. H. Andersen are with the Materials Research Division, Risø National Laboratory, Technical University of Denmark, 399 Frederiksborgvej, 4000 Roskilde, Denmark (e-mail: jean@ risoe.dtu.dk).

H. L. Suo is with the College of Materials Science and Engineering, Beijing University of Technology, Beijing 100124, People's Republic of China (e-mail: honglisuo@bjut.edu.cn).

Color versions of one or more of the figures in this paper are available online at http://ieeexplore.ieee.org.

Digital Object Identifier 10.1109/TASC.2010.2090631 to the obvious decrease of Curie temperature with increasing $\mathrm{V}$ content, the Ni-V alloy $(\mathrm{V}>9 \mathrm{at} . \%)$ has turned out to be a promising non-magnetic metallic substrate which can be manufactured with an adequate cube texture using the RABiTS (Rolling Assisted Biaxially textured substrate) method. S. Ceresara, et al. [6] and B. de Boer, et al. [11] have successfully fabricated the textured Ni-11at.\%V (Ni11V) and Ni-9at.\%V (Ni9V) substrates, respectively, using the melting route. In order to evaluate the suitability of such a non-magnetic $\mathrm{Ni}-\mathrm{V}$ substrates for epitaxial growth, the $\mathrm{YBCO} / \mathrm{CeO}_{2} / \mathrm{NiO}$ [12] and $\mathrm{YBCO} / \mathrm{CeO}_{2} / \mathrm{YSZ} / \mathrm{CeO}_{2} / \mathrm{NiO}$ [13] buffer layer and superconducting layer architectures have been selected and deposited on the Ni11V substrate by pulsed laser deposition technique. Using these two architectures, the critical current density value at $77 \mathrm{~K}$ and zero magnetic field can reach 0.6 $\mathrm{MA} / \mathrm{cm}^{2}$, which is slightly lower compared to that deposited on Ni5W substrates using the same architecture. This might be caused by intrinsic defects such as broader misorientation and twin misorientation in the Ni-V substrate that have been transferred to the YBCO layer during the epitaxial deposition process [13], [14]. Thus, in order to increase the critical current of the superconducting film grown on non-magnetic Ni-V substrates, further investigations should be oriented towards the manufacturing of Ni-V substrates free of twins and misoriented grains.

The purpose of the present work was to fabricate a non-magnetic textured Ni-12at.\%V (Ni12V) substrate by means of the powder metallurgy route which is considered to have advantages compared to the melting route. The macro- and micro- texture have been characterized by both the X-ray diffraction method and EBSD method. At the same time, the micro-hardness and the mass magnetization-temperature dependence have also been investigated to estimate the mechanical and magnetic properties of the Ni12V substrate.

\section{EXPERIMENT}

The powder metallurgy route was employed to prepare a $\mathrm{Ni}_{88} \mathrm{~V}_{12}$ ingot. The nickel powder (purity of 99.9\%) and vanadium powder (purity of $99.5 \%$ ) were weighted in stoichiometric proportions of $\mathrm{Ni}-12 \mathrm{at} . \% \mathrm{~V}$ followed by mixing homogeneously and ball milling for $72 \mathrm{~h}$. After cold isostatic pressing, the pressed bulk was annealed at $1300^{\circ} \mathrm{C}$ for 10 $\mathrm{h}$ as sintering and homogeneity treatment. The thickness of the starting ingot was $8 \mathrm{~mm}$. The cube texture was formed following the cold rolling and recrystallization annealing. The final thickness of the tape is $130 \mu \mathrm{m}$, which corresponds to a total rolling reduction of $98.4 \%$ in thickness. The tape was annealed at various temperatures ranging from $900^{\circ} \mathrm{C}$ to $1400^{\circ} \mathrm{C}$ 


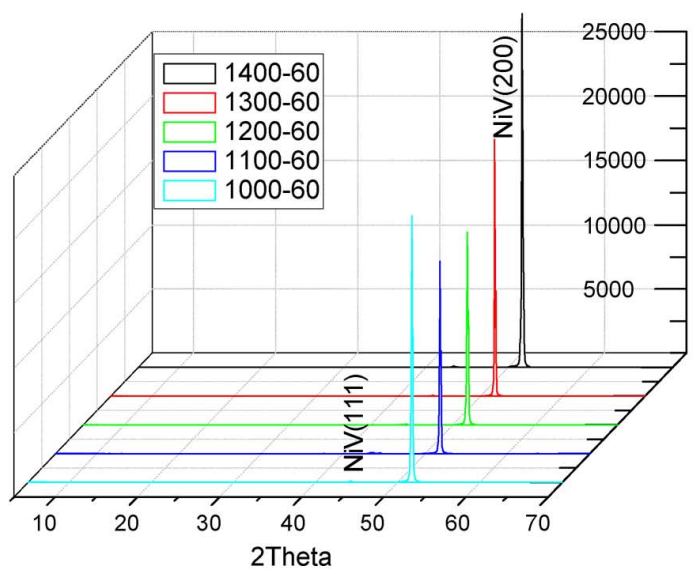

a

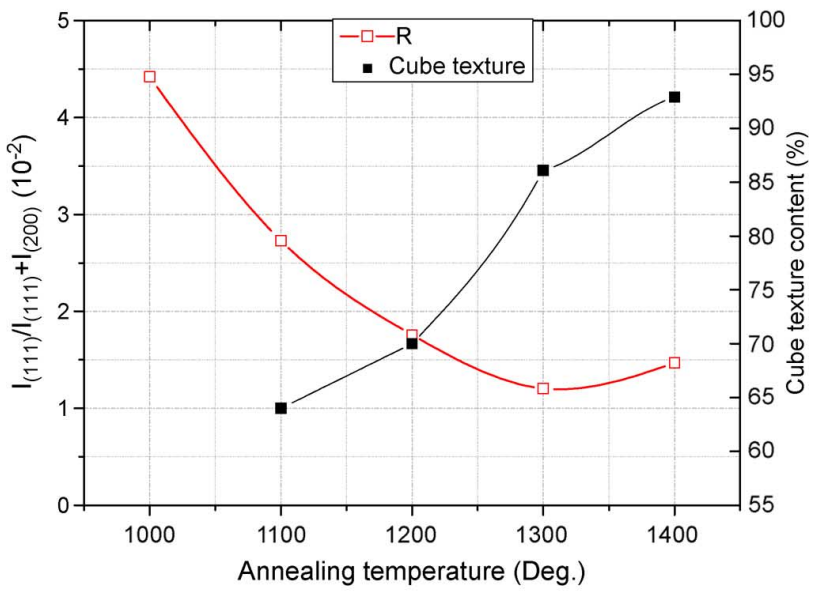

b

Fig. 1. (a) XRD profiles; (b) ratio of $\mathrm{I}_{(111)} / \mathrm{I}_{(111)}+\mathrm{I}_{(200)}$ and cube texture content of $\mathrm{Ni} 12 \mathrm{~V}$ tapes annealed at different temperatures.

for $1 \mathrm{~h}$ to evaluate the cube texture formation in a $\mathrm{N}_{2}-4 \% \mathrm{H}_{2}$ gas mixture using the two-step annealing method [15].

Texture of the recrystallized tapes was investigated with an $\mathrm{X}$-ray texture goniometer as well as with a SEM, equipped with an electron back scattering diffraction (EBSD) detector. For $\mathrm{X}$-ray analysis, the $\theta-2 \theta$ scanning and pole figure (PF) measurements were carried out.

To estimate the strength of the tapes made from different alloys, the Vickers micro-hardness HV-0.2 was measured. A VSM system was used to characterize the magnetic properties of the Ni-12at.\%V substrate.

\section{RESULTS AND DiscUSSION}

Fig. 1(a) shows the XRD patterns of the Ni12 $\mathrm{V}$ tapes annealed at temperatures between $1000^{\circ} \mathrm{C}$ and $1400^{\circ} \mathrm{C}$ for $1 \mathrm{~h}$. It is obvious that the (200) reflection peak at $50.7^{\circ}$ is the strongest reflection peak in the scanning region, which indicates that a good c-axis orientation has been obtained in all annealing conditions. At the same time, a low intensity (111) peak can be observed at $44.4^{\circ}$. In order to characterize the out-plane orientation of the annealed substrates, the value of the intensity ratio $I_{(111)}$ to $I_{(111)}+I_{(200)}$ which (hereafter is named R) has been used to quantitatively evaluate the evolution of the out of plane orientation with increasing annealing
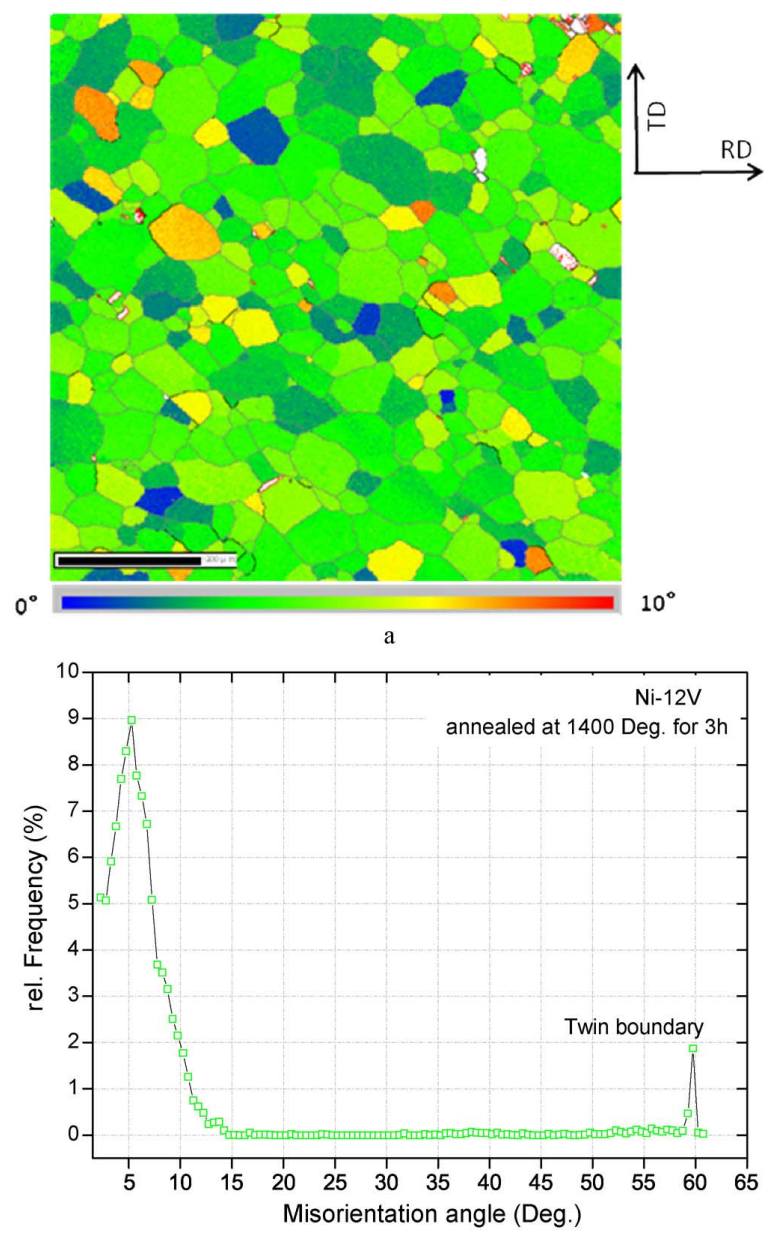

Fig. 2. The orientation distribution map a) and the GBs distribution b) of the $\mathrm{Ni} 12 \mathrm{~V}$ tape annealed at $1400^{\circ} \mathrm{C}$ for $3 \mathrm{~h}$.

temperature (Fig. 1(b)). The value of R decrease monotonically with increasing annealing temperature, which indicates that the out-plane orientation become sharper with increasing annealing temperature up to $1300^{\circ} \mathrm{C}$. In addition, the cube texture content (within a misorientation angle of $10^{\circ}$ ) also has been plotted in Fig. 1(b) as a function of annealing temperature. The result of continuous increase of cube texture content is in good agreement with the XRD result of decrease in the intensity of (111) orientation. The cube texture content can reach $92.9 \%\left(<10^{\circ}\right)$ for the Ni12 V substrate annealed at $1400^{\circ} \mathrm{C}$ for $1 \mathrm{~h}$.

In metallic textured substrates used for epitaxial deposition applications, the twins and misoriented grains have been suggested to be significantly responsible for the limitation of the critical current density in the superconducting films [13], [16]. In order to eliminate the twin and broadened cube grains, consequently, increasing the fraction of cube grains, the annealing parameters have been optimized by prolonging the dwell time to $3 \mathrm{~h}$ annealing at $1400^{\circ} \mathrm{C}$. Fig. 2(a) shows the orientation distribution of the Ni12 V substrate after full recrystallization. The cube grains within a misorientation angle of $10^{\circ}$ were colored. The cube texture content is as high as $99 \%$ as calculated from EBSD data, whereas the average grain size is $36 \mu \mathrm{m}$. Furthermore, according to the grain boundary distribution curve (Fig. 2(b)), the fraction of low angle grain boundary $\left(<10^{\circ}\right)$ can 


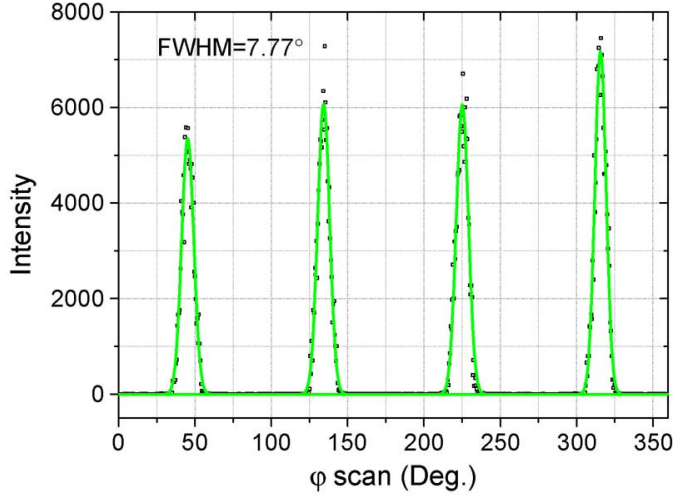

a

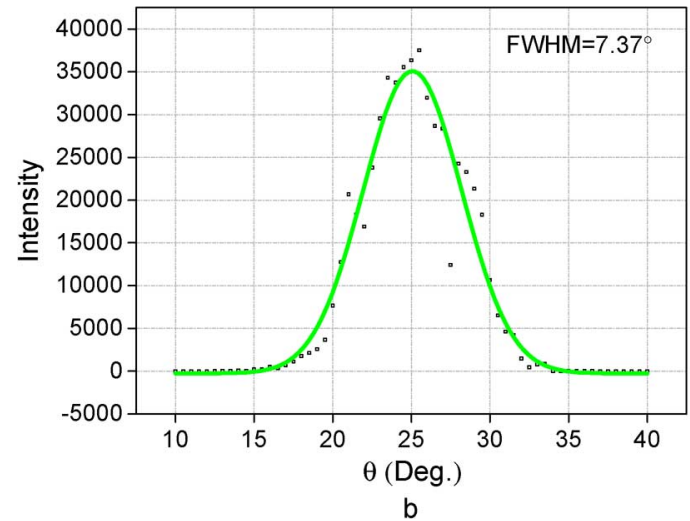

Fig. 3. The phi-scan a) and rocking curve b) of the Ni12V substrate annealed at $1400^{\circ} \mathrm{C}$ for $3 \mathrm{~h}$.

be calculated as $89 \%$. This relatively high fraction of low angle GBs is expected to be favorable for the critical current density since it could be transmitted to superconducting film by means of epitaxy. However, a small amount of twin boundaries (2.9\%) can still be detected, although it is much lower in present work than in a previous reported work with about $13.4 \%$ [17]. XRD measurements also have been carried out to evaluate the cube texture of the annealed Ni12 V substrate. From the phi-scan and rocking curve, it is found that the FWHM value is $7.77^{\circ}$ and $7.37^{\circ}$ respectively (Fig. 3). Consequently, it can be concluded that an extremely sharp cube texture has been obtained in the present Ni12V substrate, which is almost equal to the specifications of commercial Ni5W substrate.

Besides the cube texture, mechanical properties are also an important aspect for the advanced metallic textured substrate because long tapes will be subjected to strain inside the deposition chamber during continuous deposition of the buffer layers and superconducting layer. In the present work, the attention has been limited to micro-hardness at room temperature to characterize the mechanical strength of the Ni12V tape. Fig. 4 shows the micro-hardness of Ni-V alloys with different $\mathrm{V}$ contents after recrystallization as well as the micro-hardness value of the Ni5W alloy (red star) prepared by ourselves using the similar preparation solution as comparison. It is clearly shown that the micro hardness significantly increases with increasing the $\mathrm{V}$ content due to the effect of solid solution strengthening. For the Ni12V substrate, the micro-hardness value is 204 , which is three times higher than that of a pure $\mathrm{Ni}(74)$ tape as well as to a certain

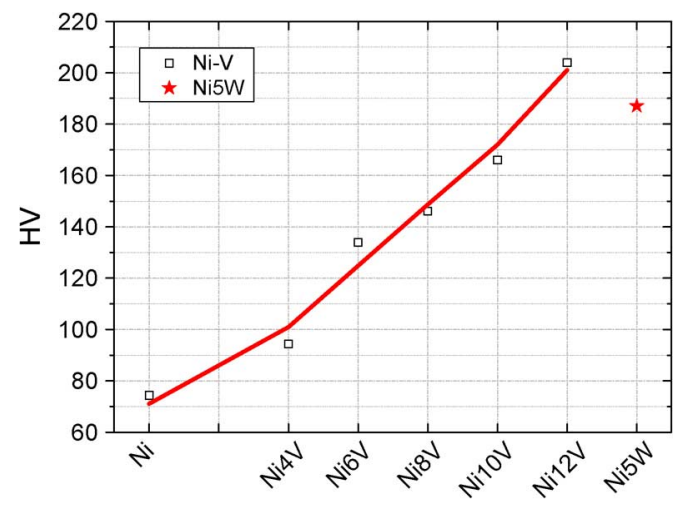

Fig. 4. The micro-hardness of a Ni5W tape and a series of Ni-V alloy tapes.

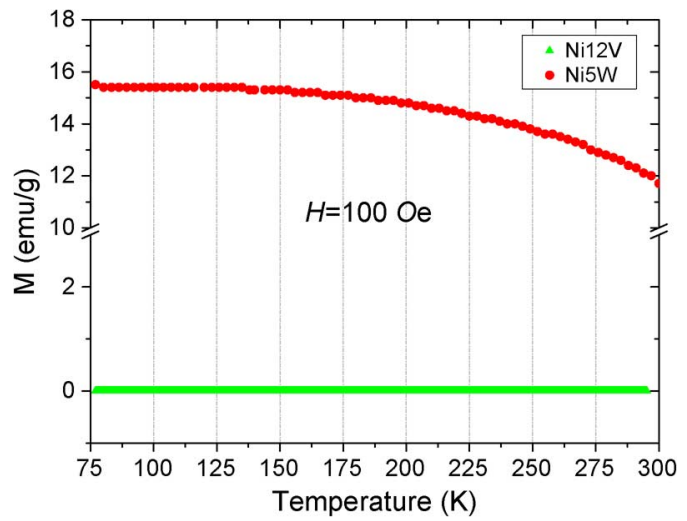

Fig. 5. Mass magnetization as a function of temperature in Ni5W and Ni12V tapes.

extent higher than that of the Ni5W alloy (187). This indicates that the mechanical strength of Ni12V substrate could satisfy the requirements for continuous deposition and may thus allow obtaining higher engineering current densities in the coated conductors.

With respect to the practical use of coated conductors, the magnetization loss should be minimized in order to diminish energy losses in alternating current (ac) applications. The temperature dependence of the mass magnetization $\mathrm{M}(\mathrm{T})$ of the Ni12V tape, together with the data of a Ni5W substrate measured in a magnetic field of 100 Oe applied parallel to the plane are shown in Fig. 5. It is found that for the Ni12V substrate the value of $\mathrm{M}$ is zero down to $77 \mathrm{~K}$. This indicates that the Curie temperature has been suppressed to below $77 \mathrm{~K}$ for the Ni12V substrate, while magnetization losses can be expected in a Ni5W substrate at $77 \mathrm{~K}$.

According to the above analysis, it is easy to conclude that the cube texture has been developed and improved successfully in the Ni12V substrate by the powder metallurgy route. Thus the Ni12V substrate which will avoid magnetization losses at $77 \mathrm{~K}$ and has a higher mechanical strength than the Ni5W substrate could be employed to deposit the buffer layers and superconducting films. As an alternative, to further improve the mechanical strength of the substrate, the Ni12V alloy could be employed as the outer layer material of a composite substrate to fabricate strengthened fully non-magnetic substrate using the multilayer fabrication technique of composite substrates 
that have been developed recently [18]-[20]. Architectures like $\mathrm{Ni} 12 \mathrm{~V} / \mathrm{Ni} 9 \mathrm{~W}$ or Ni12V/Ni12W is considered for producing such kind of substrate. Work in this direction is now in progress.

\section{CONCLUSIONS}

A non-magnetic textured Ni12V substrate has been fabricated successfully by powder metallurgy route. Firstly, the influence of annealing temperature on the cube texture formation has been investigated and optimized annealing parameters have been determined. The cube texture content of fully recrystallized Ni12V substrate is $99 \%$ within misorientation angle of $10^{\circ}$, at the same time, the fraction of low angle GBs is $89 \%$ while the twin boundary content is decreased down to $2.9 \%$. Furthermore, the FWHM value of the phi-scan and rocking curve are $7.77^{\circ}$ and $7.37^{\circ}$ respectively. These results are similar to the texture quality of commercial Ni5W substrates. Then the micro-hardness of a series of Ni-V alloys together with Ni5W has been investigated, it was found that the micro-hardness value of the Ni12V alloy is three times higher than that of pure $\mathrm{Ni}$ and to a certain extent higher than that of the Ni5W substrate. Magnetization measurements indicate that magnetization losses in the Ni12V substrate can be avoided at $77 \mathrm{~K}$. Therefore, it is strongly believed that the Ni12V substrate is a promising and competitive candidate as a low-cost, non-magnetic substrate with high quality of cube texture and good mechanical strength for large-scale coated conductor applications in the near future.

\section{ACKNOWLEDGMENT}

The authors thank M. Wishmann for his assistance to press the Ni-V ingots.

\section{REFERENCES}

[1] D. P. Norton, A. Goyal, J. D. Budai, D. K. Christen, D. M. Kroeger, and E. D. Specht et al., "Epitaxial YBCO on biaxially textured nickel (001): An approach to superconducting tapes with high critical current density," Sci., vol. 274, no. 5288, pp. 755-757, Nov. 1996.

[2] A. Goyal, M. P. Paranthaman, and U. Schoop, "The RABiTS approach: Using rolling-assisted biaxially textured substrates for high-performance YBCO superconductors," MRS Bulletin, pp. 552-561, Aug. 2004.

[3] J. Eickemeyer, D. Selbmann, R. Opitz, B. De Boer, B. Holzapfel, and L. Schultz et al., Supercond. Sci. Technol., vol. 14, pp. 152-159, 2001.

[4] W. Zhang, M. W. Rupich, U. Schoop, D. T. Verebelyi, C. L. H. Thieme, and X. Li et al., "Progress in AMSC scale-up of second generation HTS wire," Physica C, vol. 463-465, p. 505, 2007.

[5] [Online]. Available: http://www.evico.cc
[6] S. Ceresara, V. Boffa, T. Petrisor, F. Fabbri, and P. Scardi, "Textured non-magneric Ni-V10\% alloy tape for epitaxial growth of high Tc superconductors," International Journal of Modern Physics B, vol. 13, pp. 1035-1040, 1999.

[7] Z. Lockman, X. Qi, A. Barenov, W. Goldacker, R. Nast, and B. deBoer et al., "Surface oxidation of cube-textured $\mathrm{Ni}-\mathrm{Cr}$ for the formation of a $\mathrm{NiO}$ buffer layer for superconducting coated conductors," Physica C, vol. 383, pp. 127-139, 2002.

[8] J. L. Soubeyroux, C. E. Bruzek, A. Girard, and J. L. Jorda, "Thermal treatments for biaxially textured $\mathrm{Cu}-\mathrm{Ni}$ alloys for $\mathrm{YBCO}$ coated conductors," IEEE Trans. Appl. Surpercond., vol. 15, pp. 2687-2690, 2005.

[9] A. Vannozzi, A. Armenio, A. A. Angrisani, V. Galluzzi, A. Mancini, and A. Rufoloni et al., "Development and characterization of cube-textured Ni-Cu-Co substrates for YBCO-coated conductors," Acta Mater., vol. 58, pp. 910-918, 2010.

[10] U. Gaitzsch, J. Eickemeyer, R. Christian, J. Freudenberger, B. Holzapfel, and L. Schultz, "Paramagnetic substrates for thin film superconductors: Ni-W and Ni-W-Cr," Scripta, vol. 62, pp. 512-515, 2010.

[11] B. de Boer, N. Reger, G.-R. L. Fernandez, J. Eickemeyer, B. Holzapfel, and L. Schultz et al., "Biaxially textured Ni-alloy tapes as substrates for buffer and YBCO film growth," Physica C, vol. 351, pp. 38-41, 2001.

[12] G. Celentano, C. Annino, V. Boffa, L. Ciontea, F. Fabbri, and U. Gambardella et al., "Superconducting and structual properties of YBCO thick films grown on biaxially oriented $\mathrm{CeO} 2 / \mathrm{NiO} / \mathrm{Ni}-\mathrm{V}$ architecture," Physica C, vol. 341-348, pp. 2501-2502, 2000.

[13] G. Celentano, V. Boffa, L. Ciontea, F. Fabbri, V. Galluzzi, and U. Gambardella et al., "High Jc YBCO coated conductors on non-magnetic metallic substrate using YSZ-based buffer layer architecture," Physica C, vol. 372-376, pp. 790-793, 2002.

[14] F. Fabbri, C. Annino, V. Boffa, G. Celentano, L. Ciontea, and U. Gambardella et al., "Properties of biaxially oriented $\mathrm{Y} 2 \mathrm{O} 3$ based buffer layers deposited on cube textured non-magnetic Ni-V substrates for YBCO coated conductors," Physica C, vol. 341-348, pp. 2503-2504, 2000.

[15] M. M. Gao, H. L. Suo, Y. Zhao, Y. H. Zhu, L. Ma, and R. F. Fan et al., "Investigation of texture formation in Ni-7at.\%W alloy substrates by spark plasma sintering technique," IEEE Trans. Appl. Supercind., vol. 19, pp. 3279-3282, 2009.

[16] T. Petrisor, V. Boffa, G. Celentano, L. Ciontea, F. Fabbri, and V. Galluzzi et al., "Epitaxial oxidation of $\mathrm{Ni}-\mathrm{V}$ biaxially textured tapes," Physica C, vol. 377, pp. 135-145, 2002.

[17] G. Celentano, E. Varesi, T. Petrisor, V. Boffa, L. Ciontea, and V. Galluzzi et al., "Influence of the substrate microstructure on the superconducting properties of YBCO coated conductors," IEEE Trans. Appl. Supercind., vol. 13, pp. 2591-2594, 2003.

[18] Y. Zhao, H. L. Suo, M. Liu, D. He, Y. Zhang, and M. L. Zhou, "Mechanically reinforced and biaxially textured $\mathrm{Ni}$ alloy composite substrates developed by a hybrid route for coated conductors," Acta Mater., vol. 460-462, pp. 2609-2614, Sep. 2007.

[19] H. L. Suo, Y. Zhao, M. Liu, D. He, Y. Zhang, and L. Ma et al., "Technique for developing highly strengthened and biaxially textured composite substrates for coated superconductor tapes," Acta Mater., vol. 56, pp. 23-30, 2008.

[20] M. M. Gao, H. L. Suo, Y. Zhao, Y. L. Cheng, L. Ma, and R. Wang et al., "Characterization and properties of an advanced composite substrate for YBCO-coated conductors," Acta Mater., vol. 58, pp. 1299-1308, 2010. 